\title{
Anhydrous Proton Conducting poly(vinyl alcohol) (PVA)/ poly(2- acrylamido-2-methylpropane sulfonic acid) (PAMPS)/1,2,4-Triazole Composite Membrane
}

\author{
Mustafa Erkartal $^{\mathrm{a}}$, Ayse Aslan ${ }^{\mathrm{c}}$, Seyma Dadi $^{\mathrm{a}}$, Ufuk Erkilic ${ }^{\mathrm{a}}$, Ozgur Yazaydin ${ }^{\mathrm{d}}$, Hakan Usta $^{\mathrm{a}}, \mathrm{Unal} \mathrm{Sen}^{\mathrm{b} *}$ \\ aAbdullah Gül University, Department of Materials Science and Nanotechnology Engineering, 38080 Kayseri, Turkey \\ ${ }^{\mathrm{b}}$ Abdullah Gül University, Department of Mechanical Engineering, 38080 Kayseri, Turkey \\ ${ }^{\mathrm{c}}$ Gebze Technical University, Department of Bioengineering, 41400 Kocaeli, Turkey \\ ${ }^{\mathrm{d}}$ University College London, Department of Chemical Engineering, WC1E 7JE London, United Kingdom
}

\section{Abstract}

The design and fabrication of anhydrous proton exchange membranes are critically important for high temperature proton exchange membrane fuel cell (HT-PEMFC) operating between 100 and $200{ }^{\circ} \mathrm{C}$. Herein, we demonstrate a novel proton conducting membrane consisting of poly(vinyl alcohol) (PVA), poly (2-acrylamido-2-methylpropane sulfonic acid) (PAMPS) and 1,2,4-Triazole, which was fabricated by physical blending, casting and solvent evaporation techniques. The in-situ chemical cross-linking was performed by glutaraldehyde (GA) to improve the water management of the membranes. The molecular structure of the membranes and intermolecular interactions between the constituents were confirmed by Fourier-transform infrared spectroscopy (FT-IR). The surface and cross-section morphologies of the membranes were observed by scanning electron microscopy (SEM). The thermal stability performance of the membranes was studied with thermogravimetric analysis (TGA). In order to determine the physico-chemical properties of the membranes, water uptake (WU), dimensional change and ion exchange capacity (IEC) tests were carried out. The proton conductivities of composite membranes increase with the temperature and the temperature dependencies exhibit an

\footnotetext{
** Corresponding author e-mail: unal.sen@agu.edu.tr
} 
Arrhenius behavior. Proton conductivity measurements revealed an optimum ratio between PAMPS and 1,2,4-Triazole content to achieve higher proton conductivity. In anhydrous state at $150{ }^{\circ} \mathrm{C}$, the highest proton conductivity measured was $0.002 \mathrm{~S} / \mathrm{cm}$ for PVA:PAMPS:1,2,4Triazole (1:1:1) composition. Overall, our investigation showed that $1,2,4$-Triazole is a promising proton carrier reagent above $100{ }^{\circ} \mathrm{C}$ when it is embedded into appropriate host polymers.

Keywords: PVA, PAMPS, Triazole, PEMFC, Proton Conducting

\section{Introduction}

Since the beginning of the $20^{\text {th }}$ century, the excessive uses of fossil fuels have led to negative consequences on the environment and climate. In order to address this global issue alternative clean energy resources and their environmentally friendly utilization need to be discovered. To this end hydrogen is an environmentally friendly fuel, which has been proposed as an alternative to fossil fuels. Polymer electrolyte membrane fuel cell (PEMFC) is an electrochemical device in which chemical energy of a fuel is directly converted into electricity. When hydrogen is used in PEMFC as the fuel, its inherent chemical energy is converted into electricity with higher efficiencies in comparison with the conversion of fossil fuels in thermal plants and internal combustion engines. On the other hand, hydrogen fueled PEMFCs produce zero pollutants, because the byproducts of this reaction occurring in PEMFCs are only water and heat. [1]

In a typical PEMFC, one of the most important components of the device is the electrolyte membrane which provides proton (e.g. $\mathrm{H}^{+}$) conduction between anode and cathode. Today, the most common membranes are based on the perfluorosulfonic acid, and the most well-known example is Nafion $®$, which is manufactured by Dupont. It has high 
thermal, mechanical and dimensional stability, and shows high proton conductivity. Nevertheless, because of high water dependency of proton conductivity, the operation temperature of a PEMFC with Nafion ${ }^{\circledR}$ is restricted up to $100{ }^{\circ} \mathrm{C}$. [2]

Several problems emerge during the operation of a PEMFC at low temperatures. The major challenges in this case are as follows: (i) poor electrode performance because of the slow reduction kinetics of oxygen at the cathode, (ii) low tolerance to fuel impurities (e.g. $\mathrm{CO}$ ), (iii) need for complex liquid water and thermal management system, and (iv) low overall system efficiency due to limited recovery of the heat. Yet at high temperatures, high temperature proton exchange fuel cells (HT-PEMFCs), which correspond to an operation temperature ranging from 100 to $200{ }^{\circ} \mathrm{C}$, are a promising technology which can prevail over these challenges. $[1,3,4]$

On the other hand, the operation of PEMFCs at high temperatures requires advanced membrane, with desired physical and chemical properties. To date great efforts have been made to develop novel proton exchange membranes which can operate in anhydrous conditions with high proton conductivity at high temperatures. One of the most effective methods among them relies on the preparation of the acid-base complexes. The backbones of the polymers, which are used in such a complex, react with acids. In such a reaction, the polymer's backbone acts as a proton acceptor and this result in an ion pair formation. $[1,3]$ There is a rich literature on poly (vinylpyrrolidone) (PVP) [5, 6], poly (ether ether ketone) (SPEEK)[7-9], polyethyleneoxide (PEO)[10] and polybenzimidazole (PBI) [3, 11]based membranes. Several studies have revealed that amphoteric acid, which can act both as an acid and as a base, enhances the proton conductivity of the membrane. The typical amphoteric acids used in such studies are phosphoric and phosphonic acids, which enable dynamic hydrogen bonding and breaking due to the dual behavior. [12] However, these kind of polymer-acid structures have had some limitations and drawbacks in several ways. For 
instance, excessive acid contents in the polymer causes gel-like formation, so membrane could not be cast. Moreover, most of these acid-base complex structures reported in the literature have demonstrated proton conductivities less than $10^{-3} \mathrm{~S} / \mathrm{cm}$. [13-15]

Recently, the design of composite structures in which a polymer is combined with aromatic heterocycles such as imidazole, triazole have attracted much attention. It is thought that these heterocycles assist in proton conduction via intermolecular proton transfer, and thus they can be used to substitute water as a proton carrier in the HT-PEMFC membrane. When compared with imidazole, 1,2,4-triazole has received attention as proton carrier reagent due to its higher melting point $\left(120{ }^{\circ} \mathrm{C}\right)$, lower $\mathrm{p} K_{\mathrm{a}} \quad\left(\mathrm{pK}_{\mathrm{a} 1} 2.39, \mathrm{pK}_{\mathrm{a} 2}\right.$ 9.97), and nitrogen-rich structure. Previous research has documented that pure 1,2,4-triazole has proton conductivity about $5 \times 10^{-4} \mathrm{~S} / \mathrm{cm}$ at $115{ }^{\circ} \mathrm{C}$ and $1.2 \times 10^{-3} \mathrm{~S} / \mathrm{cm}$ at its melting temperature, $120{ }^{\circ} \mathrm{C} .[13,15-$ 18] In our previous paper, we demonstrated anhydrous proton conducting membranes prepared by embedding azole reagents into Nafion for use in HTPEMFC. In that work, the highest proton conductivity reported for the Nafion 115/1, 2, 4-Triazole composite membrane was $7.74 \times 10^{-4} \mathrm{~S} / \mathrm{cm}$ at $180^{\circ} \mathrm{C} .[18]$

In this study, we demonstrate that the synthesis of a new composite membrane consisting of poly(vinyl alcohol), poly(2-acrylamido-2-methylpropane sulfonic acid) (PAMPS) and 1,2,4-Triazole, which exhibit high proton conductivity under anhydrous conditions and also good chemical and thermal properties. In our design, PVA is used as the host constituent owing to its good film-forming ability, chemical stability, mechanical strength, and cost efficiency. To improve the swelling properties of the membrane, the chemical cross-linking was carried out by using glutaraldehyde (GA), and the chemical crosslinking takes place between aldeyhde groups of GA and hydroxyl groups of PVA to form acetals.[2, 19-21] Adding PAMPS increases the density of charge carriers in the membrane and generate favorable proton-transfer pathways by forming hydrogen bonding with 1,2,4- 
triazole molecules. [13] Similar to PVA, PAMPS acts as the host polymer and its chains provide the immobilization of small 1,2,4-Triazole molecules by trapping them throughout the membrane. It's noteworthy that PAMPS also acts as the catalyst for the acid-catalyzed crosslinking reaction between PVA and GA. [20] 1,2,4-triazole is the primary proton carrier agent in the new membrane systems thanks to its nitrogen-rich structure and easily hydrogen bonds forming ability, hence a promising agent to replace the use of water above $100{ }^{\circ} \mathrm{C}$. [13-15]

\section{Experimental}

\subsection{Materials}

PAMPS (Mw $=2000$ 000, 15 wt \% in aqueous), PVA $(\mathrm{Mw}=89000-98000$, more than $99 \%$ hydrolyzed), 1,2,4-Triazole (98\% purity) and Gluturaldeyde solution (GA, 25 wt \% aqueous) were purchased from Sigma-Aldrich. Methanol with $99.9 \%$ purity was purchased from Merck. Distilled water was used in the experiments.

\subsection{Membrane preparation}

The PVA/PAMPS/1,2,4-Triazole based composite membranes were formed by solution casting and solvent evaporation method. At the first step, $3 \mathrm{~g}$ PVA powder was fully dissolved in $100 \mathrm{ml}$ distilled water (DW) at at $80{ }^{\circ} \mathrm{C}$ by stirring to yield a homogenous solution. Simultaneously, $4 \mathrm{~g}$ 1,2,4-Triazole was dissolved in $100 \mathrm{ml}$ methanol $(\mathrm{MeOH})$ at room temperature. Then certain amount of $1,2,4-\mathrm{Triazole} / \mathrm{MeOH}$ was poured into certain amount of PVA/DW solution. The solution was vigorously stirred for overnight. Next, appropriate amount of PAMPS was diluted in DW and slowly added into the prepared solution. Final solution was vigorously stirred for overnight. In the last of step of the preparation of the solution, the chemical cross-linking was performed in situ by adding $0.1 \mathrm{ml}$ 
GA (25 wt \% in water). It should be noted that no extra acidic catalyst was needed for the cross-linking reaction due to the fact that the reaction was catalyzed by PAMPS. Finally, the prepared solutions were cast onto glass petri dishes. Films on the petri dishes were put in a chemical hood under ventilation for overnight and then placed in vacuum oven ( 100 mTorr) at $70{ }^{\circ} \mathrm{C}$ for $4 \mathrm{~h}$, so as to evaporate residual solvents in the cast films. The resulting compositions of PAMPS:1,2,4-Triazole in all films were (1:0.5), (1:1), and (1:2) in terms of weight. Fig. 1 illustrates the preparation steps of the composite membranes and the images of membranes obtained. 


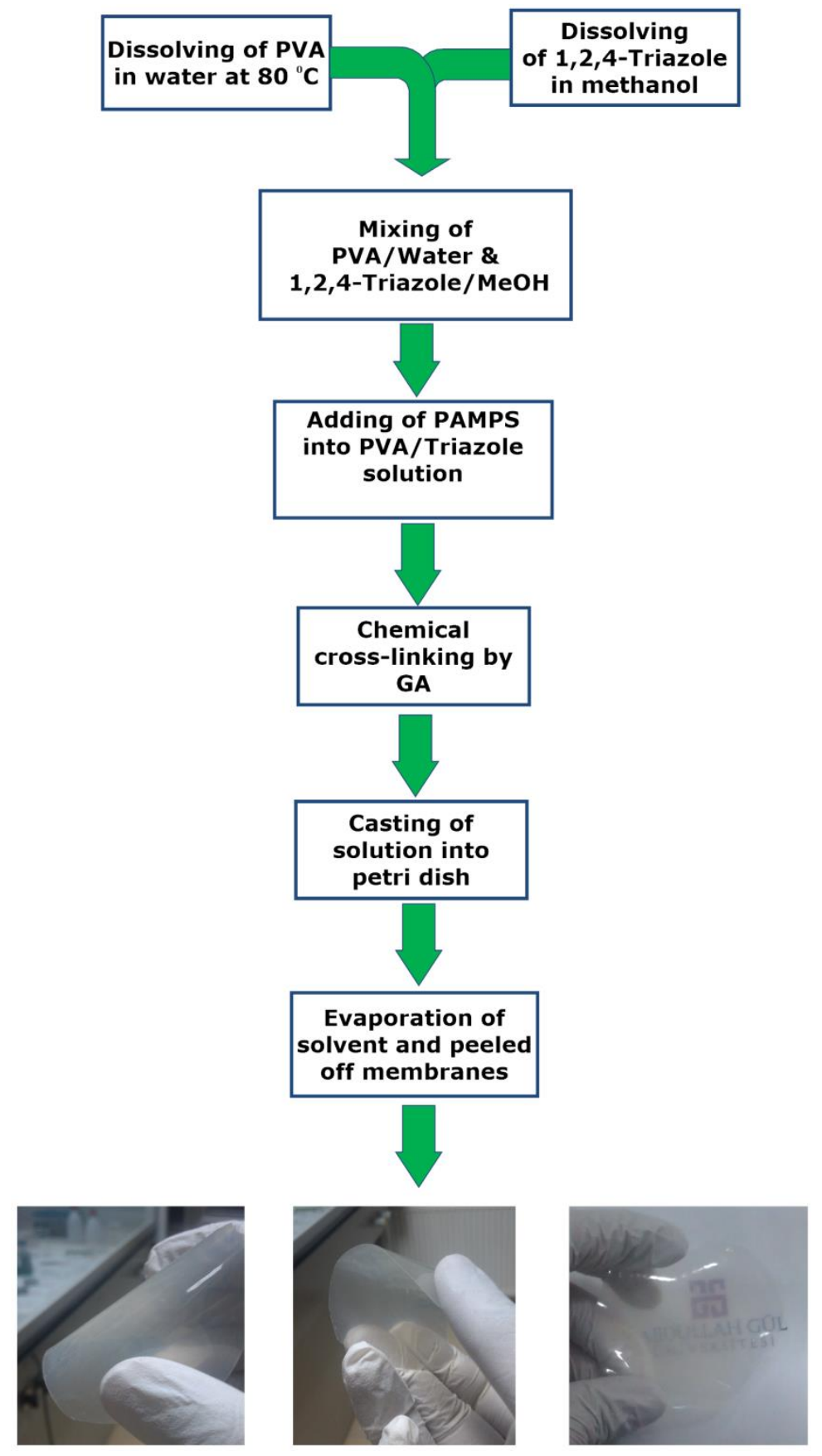

Fig. 1. Preparation steps of the composite membranes and images of the membranes prepared demonstrating flexibility and transparency. 


\section{Characterization}

Fourier Transform Infrared Spectroscopy (FT-IR)

The prepared membranes were examined by Attenuated Total Reflectance Fourier Transform Spectroscopy (ATR-FTIR) on Thermo Nicolet 6700. Spectrum was obtained with $4 \mathrm{~cm}^{-1}$ resolution between 400 and $4000 \mathrm{~cm}^{-1}$.

Scanning Electron Microscopy (SEM)

The Scanning electron microscope (SEM) (Zeiss EVO LS 10) was used for the morphological analysis of PVA/PAMPS/1,2,4-Triazole membranes. To prove the homogenous distributions of constituents in the composite membranes, surfaces and crosssections were examined.

Thermogravimetric (TG) Analysis

Thermal stability of the membranes were examined by Shimadzu DTG 60 . Before the measurements, all membranes were held at $65{ }^{\circ} \mathrm{C}$ under vacuum for $12 \mathrm{~h}$. All thermal measurements were carried out under nitrogen at a heating rate of $10{ }^{\circ} \mathrm{C} \mathrm{min}^{-1}$.

Water Uptake and Dimensional Stability Analysis

The water uptake (WU) studies of the prepared membranes were performed in accordance with a reported procedure[22]; square pieces of the membrane samples with known dimensions $\left(1 \times 1 \mathrm{~cm}^{2}\right.$ square pieces $)$ were dried at $65^{\circ} \mathrm{C}$ to evaporate residual solvent, and then weighed. Next, dry membranes were soaked in DW for $24 \mathrm{~h}$, surface water was properly wiped by a filter paper and weighed. Water uptake of the membranes was calculated by using the following equation (Eq. 1): 
$W U=\frac{\left(W_{w e t}-W_{d r y}\right)}{W_{d r y}}(1)$

where $\mathrm{W}_{\text {wet }}$ and $\mathrm{W}_{\text {dry }}$ are the wet and dry masses of the membranes.

Similarly, dimensional changes in the membranes were studied by the same procedure. The changes of ratio were calculated by using following equations (Eq. 2):

$$
\begin{aligned}
& \Delta L=\frac{\left(L_{w e t}-L_{d r y}\right)}{L_{d r y}} \\
& \Delta W=\frac{\left(W_{w e t}-W_{d r y}\right)}{W_{d r y}}(2) \\
& \Delta T=\frac{\left(T_{w e t}-T_{d r y}\right)}{T_{d r y}}
\end{aligned}
$$

where $\mathrm{L}, \mathrm{W}$, and $\mathrm{T}$ are dimensions of the membranes in length, width, and thickness, respectively. The dimensions of the membranes were measured by using electronic calipers. The swelling experiments were repeated three times to make sure the accuracy.

\section{Ion-Exchange Capacity}

The ion exchange capacity (IEC) values of the prepared membranes were determined by titration following a reported procedure[22]. Firstly, the sample pieces were cut from the membrane and dried at $65^{\circ} \mathrm{C}$ under vacuum. Then, membranes were immersed in $25 \mathrm{~mL}$ of $2 \mathrm{M} \mathrm{NaCI}$ aqueous solution to replace the $\mathrm{H}^{+}$by $\mathrm{Na}^{+}$. Afterwards, the solution was titrated with $0.1 \mathrm{M} \mathrm{NaOH}$ solution using a phenolphthalein indicator. The IEC is expressed in terms of milliequivalents of sulfonic groups per gram of dried sample. The IEC experiments were repeated three times in order to ensure the accuracy. 
Proton conductivity measurements of the prepared membranes were performed using a Novocontrol dielectric-impedance analyzer. The films were sandwiched between platinum blocking electrodes and the conductivities were measured in the $1 \mathrm{~Hz}$ to $3 \mathrm{MHz}$ frequency range as a function of temperature between 20 and $150{ }^{\circ} \mathrm{C}$ with $10{ }^{\circ} \mathrm{C}$ intervals. Before the measurements, all membranes were held at $65^{\circ} \mathrm{C}$ under vacuum for $12 \mathrm{~h}$.

\section{Results and discussions}

\section{PVA/PAMPS/Triazole membrane structure}

All of the membranes prepared in this study, regardless of their composition, are colorless, transparent and flexible. The measured thicknesses of membranes by electronic caliper are between 90 and $150 \mu \mathrm{m}$. Fig. $2 \mathrm{~b}$ illustrates the proposed structure for the obtained membranes. In our design, while PVA and PAMPS are the host polymers of the composite membranes, small 1,2,4-Triazole molecules are trapped in the polymer matrix. They are homogenously dispersed through the membrane. To enhance the mechanical properties and water resistance of the membranes, a chemical cross-link was performed on PVA. The crosslinking reactions occur between aldeyhde groups $(-\mathrm{CHO})$ of GA and hydroxyl groups $(-\mathrm{OH})$ of PVA to form cylic acetals. In the membrane, the sulfonic acid groups $\left(-\mathrm{SO}_{3} \mathrm{H}\right)$ on PAMPS backbone and (-NH) groups in 1,2,4-triazole participate in the proton conduction along the membranes by structural diffusion. 
a<smiles>CC(C)(C)CC(O)C(C)(C)C</smiles><smiles>O=CCCCC=O</smiles>

GA
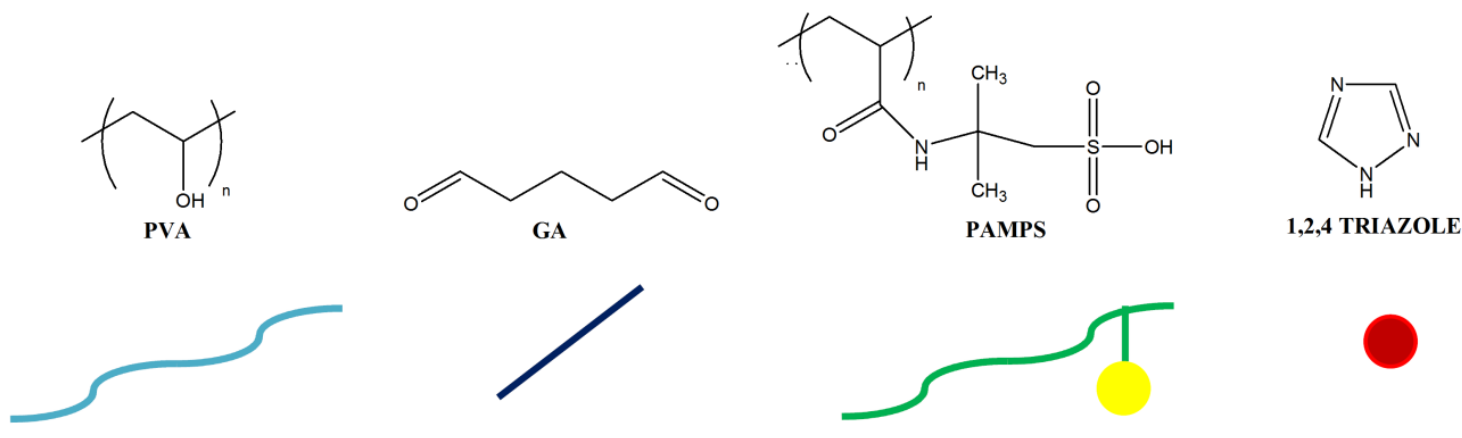

$1,2,4$ TRIAZOLE

b

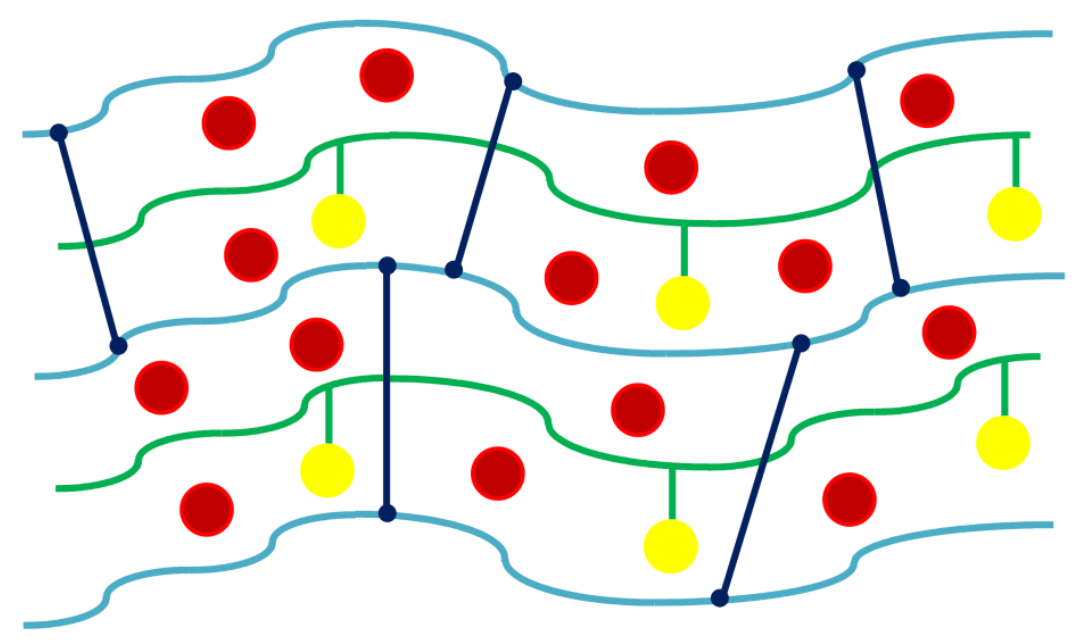

C

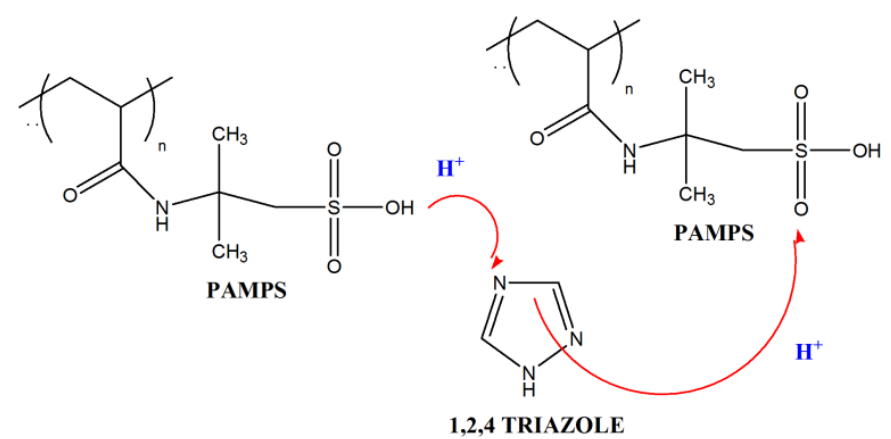

Fig. 2a.The chemical structures of PVA, GA, PAMPS, and 1,2,4-triazole. 2b. The proposed membrane microstructure for the cross-linked PVA/PAMPS/1,2,4-triazole. 2c. The proposed proton transfer path along PAMPS chains and 1,2,4-triazole molecules. 


\section{Fourier Transform Infrared Spectroscopy (FT-IR)}

ATR/FT-IR was used to provide information about molecular structure of PVA/PAMPS/1,2,4-Triazole membranes and confirm the existence of cross-linking reactions between PVA and GA. Fig. 3 shows the transmittance FT-IR spectra of the membranes and its individual constituents. The broad absorption peaks arise at around $3500 \mathrm{~cm}^{-1}$ and $3000 \mathrm{~cm}^{-1}$ in all spectra correspond to $(\mathrm{O}-\mathrm{H})$ stretching in PVA and PAMPS, and asymmetrical stretching of metyhlene (C-H) group in PVA, respectively. [2, 19, 20, 23] The peaks at around $3120 \mathrm{~cm}^{-1}$ are associated with $(\mathrm{N}-\mathrm{H})$ stretching in 1,2,4-triazole units. $[14,15,18,24]$ The sharp peaks at about $1635 \mathrm{~cm}^{-1}$ and $1550 \mathrm{~cm}^{-1}$ are attributed to vibrations of $(\mathrm{C}=\mathrm{O})$ and $(\mathrm{N}-\mathrm{H})$ groups in PAMPS, respectively. The sharp peaks at around $1130 \mathrm{~cm}^{-1}$ are assigned to (S-O) stretching of sulfonic acid groups in PAMPS. Likewise, the weak signal at $840 \mathrm{~cm}^{-1}$ corresponds to the bending of $(\mathrm{O}-\mathrm{H})$ due to free $(-\mathrm{CHO})$ groups coming from excess $\mathrm{GA}$. [2, 20] An important implication of the FT-IR spectra is that as the amount of 1,2,4-triazole in the membranes increases, the relative intensity of the signals coming from PAMPS decreases. This result may be explained by hydrogen bonding between $(\mathrm{N}-\mathrm{H})$ group in 1,2,4-triazole ring and $(\mathrm{O}-\mathrm{H})$ and $(\mathrm{N}-\mathrm{H})$ in PAMPS. Conversely, the formation of hydrogen bond between hydroxyl groups of PVA and sulfonic acid groups in PAMPS could not be observed separately because of the overlapping of hydrogen bonding between $-\mathrm{SO}_{3} \mathrm{H} \cdots \mathrm{HO}-$ and OH...HO-.[25] The detailed FT-IR spectra are summarized in Table 1. 


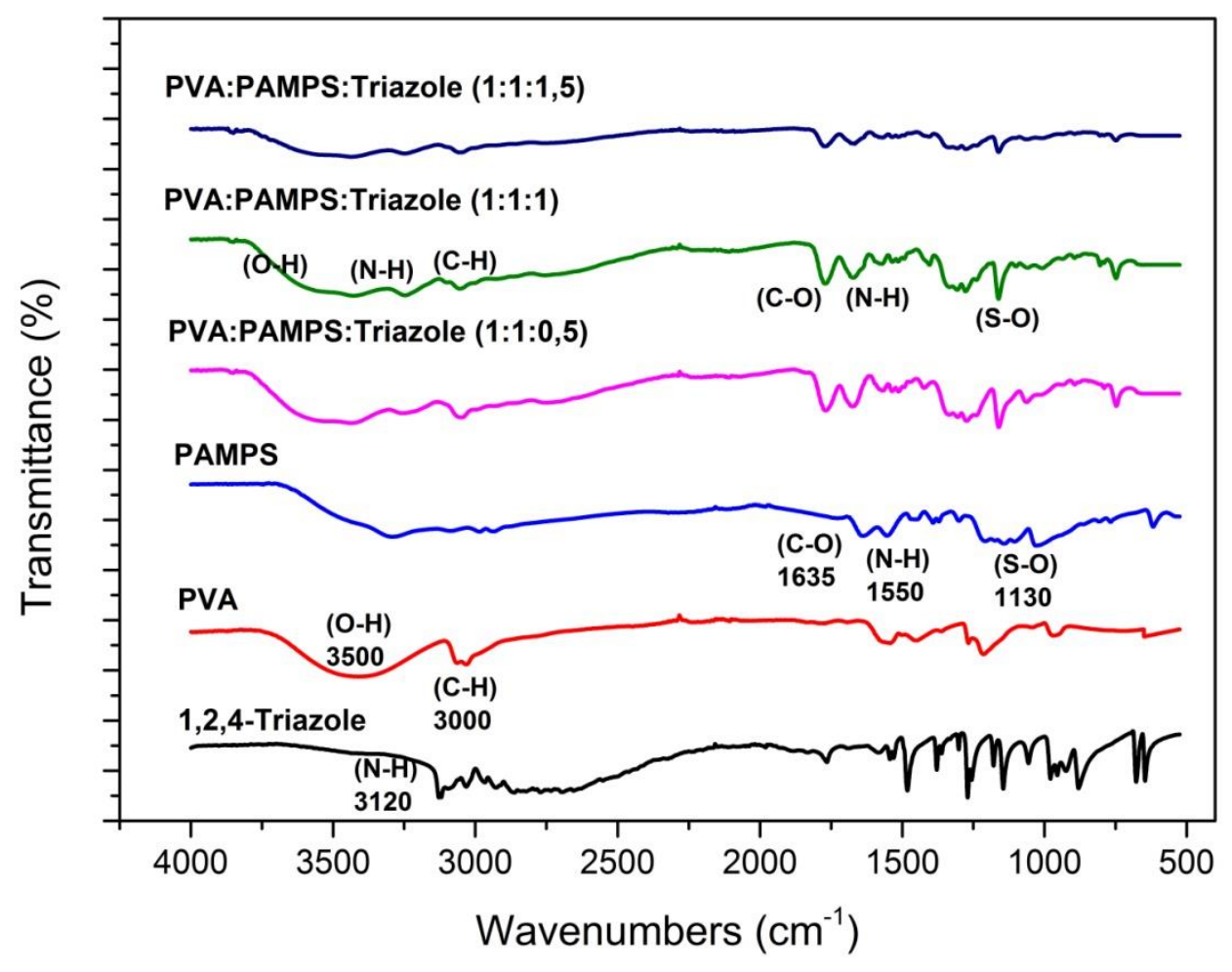

Fig. 3. FT-IR spectra of the composite membranes with different compositions and individual constituents.

\begin{tabular}{ll}
\hline Wavenumber $\left(\mathbf{c m}^{-1}\right)$ & Attributions \\
\hline $\mathbf{3 5 0 0}-\mathbf{3 6 0 0}$ & $v(\mathrm{O}-\mathrm{H})$ \\
$\mathbf{3 2 0 0}-\mathbf{1 5 5 0}$ & $v(\mathrm{~N}-\mathrm{H})$ \\
$\mathbf{3 0 5 0}$ & $v(\mathrm{C}-\mathrm{H})$ \\
$\mathbf{1 7 7 0 - 8 0 0}$ & $\delta(\mathrm{N}-\mathrm{H})$ \\
$\mathbf{1 6 3 5}$ & $v(\mathrm{C}=\mathrm{O})$ \\
$\mathbf{1 1 3 0}$ & $v\left(\mathrm{SO}_{3}\right)$ \\
$\mathbf{8 4 0}$ & $v(\mathrm{C}-\mathrm{OH})$ \\
\hline
\end{tabular}

Table 1.FT-IR absorption peaks for PVA:PAMPS:1,2,4-Triazole composite membranes. 


\section{Morphology}

Fig. 4 shows the surface and cross-sectional SEM images of composite membranes with three different 1,2,4-Triazole compositions. Surface morphologies show that all constituents of the membranes in each composition are homogeneously distributed through the membranes in the lateral direction without causing any notable phase segregation. From Fig. 4 (a,b,c) it can be also seen that the surface roughness of the membranes gradually increases with increasing 1,2,4-triazole concentration. This is explained based on the fact that in comparison to long polymer chains, small 1,2,4-triazole molecules are highly-likely to seep out from the polymer matrix. Cross-sectional views indicate that membranes have a uniform morphology and microstructure along the cross section and there is no sign of void or agglomeration at the inter-phases. The cross-sectional images show that the thickness of the membranes changes between $80-150 \mu \mathrm{m}$ depending on the compositions.

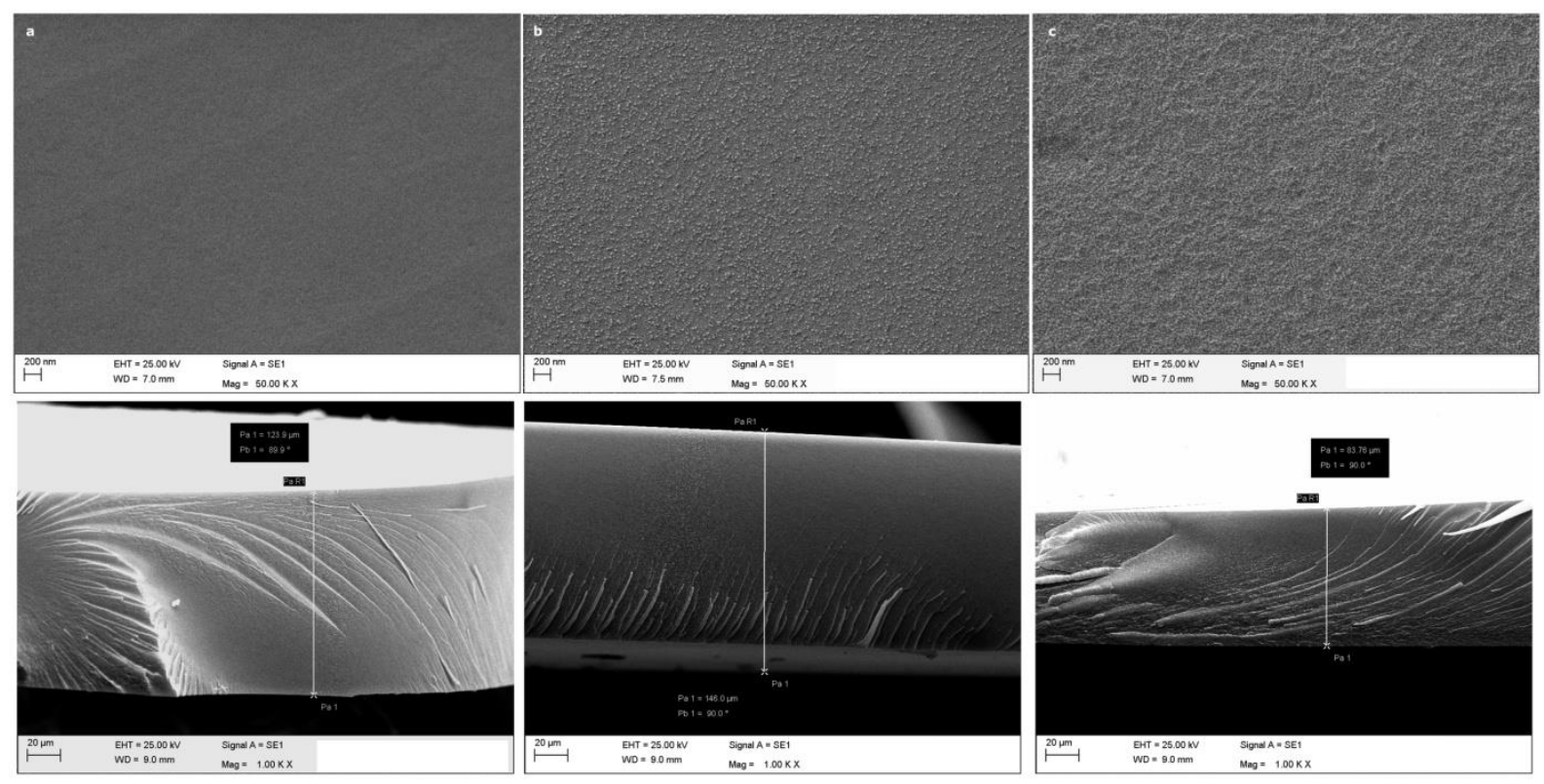

Fig. 4.Surface and cross-sectional SEM micrographs of the composite membranes with different 1,2,4Triazole compositions: (a) PVA:PAMPS:Triazole (1:1:0.5), (b) PVA:PAMPS:Triazole (1:1:1), and (c) PVA:PAMPS:Triazole $(1: 1: 1.5)$ 


\section{Thermogravimetric analysis}

The prepared composite membranes have to be thermally stable at high temperatures due to the operation temperatures of HT-PEMFCs $\left(100-200{ }^{\circ} \mathrm{C}\right)$. As the host polymers in the designed membranes, PVA and PAMPS have high thermal stability and low thermal volatility up to $300{ }^{\circ} \mathrm{C}$ and $200{ }^{\circ} \mathrm{C}$, respectively. On the other hand, proton conductive organic reagent 1,2,4-triazoles shows thermal stability up to $250{ }^{\circ} \mathrm{C}$ due to strong hydrogen bonding in its structure. Fig. 5 presents the thermal degradation micrographs of the composite membranes with different 1,2,4-triazole loadings. An initial linear drop in weight between approximately $120{ }^{\circ} \mathrm{C}$ and $190{ }^{\circ} \mathrm{C}$ corresponds to evaporation of water from the membrane. Then, two decomposition steps can be observed for each membrane. The first major decomposition step occurs between 190 and $300{ }^{\circ} \mathrm{C}$. This stage corresponds to the degradation of sulfonic acid groups $\left(-\mathrm{SO}_{3} \mathrm{H}\right)$ in PAMPS and the degradation of 1,2,4-triazole inside the membranes. Likewise, the cleavage of side chain of PVA occurs in this region. The second decomposition stage starts at $350{ }^{\circ} \mathrm{C}$ and finishes at $450{ }^{\circ} \mathrm{C}$, which is attributed to the cleavage of the backbone of the PVA. [2, 14, 20, 23, 25] Thermal decomposition onsets are taken as $5 \%$ of the weight after initial water loss, which corresponds to $220{ }^{\circ} \mathrm{C}$ for membrane (1:1:0.5), 205 ${ }^{\circ} \mathrm{C}$ for membrane $(1: 1: 1)$, and $177{ }^{\circ} \mathrm{C}$ for membrane (1:1:1.5). Thermal degradation analysis points out two major results: (i) the thermal stability of the membranes decreases with the increasing of 1,2,4-Triazole content, and (ii) in terms of thermal stability, the most stable membrane is PVA:PAMPS:Triazole (1:1:0.5). Based on these results it is possible to conclude that the membrane with $(1: 1: 1)$ composition shows thermal stability up to $200{ }^{\circ} \mathrm{C}$ so it is thermally suitable for use as a membrane in the HT-PEMFC. 


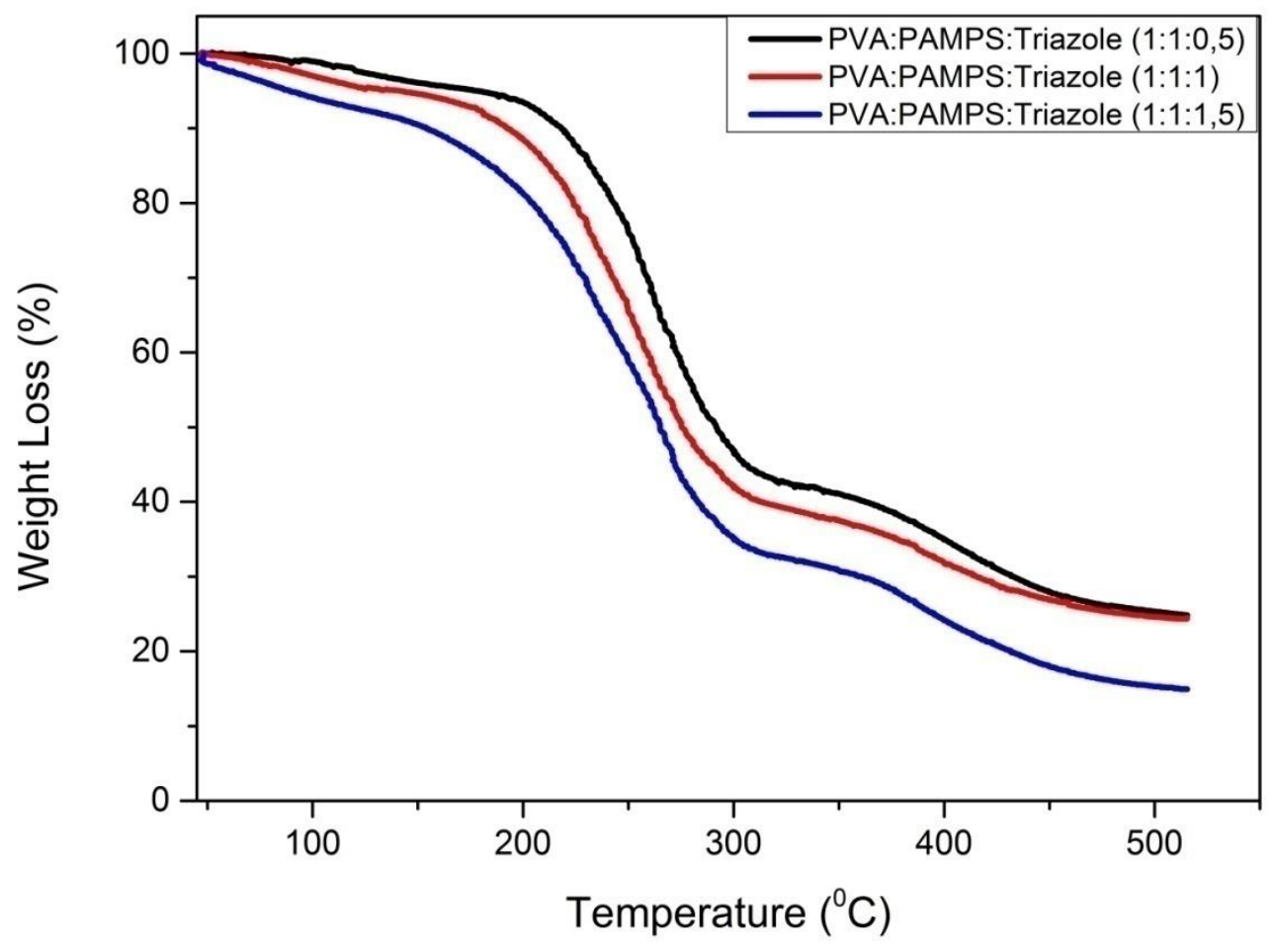

Fig. 5.Thermogravimetric (TGA) thermographs of the composite membranes.

\section{Physico-chemical characteristics of the membranes}

Swelling behavior, or water uptake (WU), has an essential function for both proton migration and dimensional stability of a membrane. Specifically, in the case of anhydrous proton conduction, this value is especially important to determine the dimensional stability of membrane during the operation conditions in HT-PEMFC. The water uptake values and the changes in dimensions of the membranes are presented in Table 2. The hydrophilic character of each constituent determines the overall water uptake performance of the membrane. Because of the hydrophilic hydroxyl $(-\mathrm{OH})$ groups in its structure, PVA shows a large water affinity, yet the chemical cross-linking by GA causes greater flexibility of the polymer chains and allows the presence of more water molecules between the polymer chains. Also, sulfonic acid groups $\left(-\mathrm{SO}_{3} \mathrm{H}\right)$ in PAMPS are very hydrophilic. [2, 20, 26] Although 1,2,4-Triazole 
molecules show hydrophilic characteristics, WU values of the membranes did not change by the 1,2,4-triazole content. The reason is that small 1,2,4-triazole molecules are tightly trapped between the cross-linked PVA and long PAMPS chains, hence they may not contribute the swelling behavior of the membrane significantly. Nevertheless, the membrane with PVA:PAMPS:1,2,4-Triazole (1:1:1.5) composition has a slightly higher WU value than the others. The most likely explanation of this phenomena is that, as can also be seen from SEM images, the excessive 1,2,4-triazole content couldn't be trapped throughout the membrane, and more hydrophilic sites available on the surface, and thus resulted in capturing of more water inside the membrane.

The overall dimensional swelling measurements of the membranes are summarized in Table 2. The results show that the changes in lengths of the membrane because of swelling were found to be almost the same in all directions ( $\mathrm{L}, \mathrm{W}, \mathrm{T})$ which indicates the isotropic property. Moreover, based on these results, it can be concluded that all membranes show good dimensional stability when they are exposed to water.

The ion exchange capacity (IEC) is about the number of exchangeable ion groups in the membrane. IEC is commonly given in terms of the moles of fixed $-\mathrm{SO}_{3}{ }^{-1}$ sites per gram of polymer. Since the charge density increases in the membrane, the proton conductivity increases with increasing IEC. In our design, the only ion source for $-\mathrm{SO}_{3}^{-1}$ is PAMPS polymer, which is present at the same concentration in all membranes, so it is expected to have similar IEC values for all membranes. The IEC values of the prepared membranes are demonstrated in Table 2. As expected, IEC values obtained by titration are almost equal to each other and consistent with the literature values. $[2,13,20]$ 


\begin{tabular}{|l|l|l|l|l|l|l|l|l|}
\hline $\begin{array}{l}\text { PVA:PAMPS:1,2,4 } \\
\text { Triazole } \\
\text { Ratio }\end{array}$ & IEC & $\begin{array}{l}\text { Water } \\
(\mathrm{meq} / \mathrm{g})\end{array}$ & $\begin{array}{l}\text { Uptake } \\
(\mathrm{g} / \mathrm{g})\end{array}$ & $\begin{array}{l}\Delta \mathrm{L} \\
(\mathrm{cm} / \mathrm{cm})\end{array}$ & $\begin{array}{l}\Delta \mathrm{W} \\
(\mathrm{cm} / \mathrm{cm})\end{array}$ & $\Delta \mathrm{T}$ & $\begin{array}{l}\mathrm{n} \\
(\mathrm{cm} / \mathrm{cm})\end{array}$ & $\begin{array}{l}\text { Proton } \\
\left./ \mathrm{SO}_{3} \mathrm{H}\right)\end{array}$ \\
$\begin{array}{l}\text { Conductivity } \\
(\mathrm{S} / \mathrm{cm})\end{array}$ & $\begin{array}{l}\text { Activation } \\
\text { Energy } \\
(\mathrm{kJ} / \mathrm{mol})\end{array}$ \\
\hline $1: 1: 0.5$ & $\mathbf{1 . 6 2}$ & $\mathbf{2 . 4 2}$ & $\mathbf{0 . 2 4}$ & $\mathbf{0 . 2 8}$ & $\mathbf{0 . 2 1}$ & $\mathbf{1 . 5}$ & $\mathbf{2 \times 1 0 ^ { - 5 }}$ & $\mathbf{1 4 . 1 7}$ \\
\hline $1: 1: 1$ & $\mathbf{1 . 6 2}$ & $\mathbf{2 . 4 8}$ & $\mathbf{0 . 3 0}$ & $\mathbf{0 . 3 1}$ & $\mathbf{0 . 2 4}$ & $\mathbf{3}$ & $\mathbf{2 \times 1 0 ^ { - 3 }}$ & $\mathbf{1 7 . 7 5}$ \\
\hline $1: 1: 1.5$ & $\mathbf{1 . 6 1}$ & $\mathbf{2 . 7 4}$ & $\mathbf{0 . 4 1}$ & $\mathbf{0 . 3 9}$ & $\mathbf{0 . 3 6}$ & $\mathbf{4 . 5}$ & $\mathbf{7 \times 1 0 ^ { - 6 }}$ & $\mathbf{8 . 4 0}$ \\
\hline
\end{tabular}

Table 2.Physico-chemical properties of the composite membranes.

\section{Proton Conductivity}

Proton conductivity measurements of the membranes were performed by impedance spectroscopy so as to investigate their potential for use in HT-PEMFCs. Frequency dependent AC conductivities of the membrane $\left(\sigma_{\mathrm{ac}}(\omega)\right)$ were calculated from the following equation (Eq. 3):

$\sigma^{\prime}(\omega)=\sigma_{\mathrm{ac}}(\omega)=\varepsilon^{\prime \prime}(\omega) \omega \varepsilon_{\mathrm{o}}(3)$

where $\sigma^{\prime}(\omega)$ is the real part of conductivity, $\omega=2 \pi f$ is the angular frequency, $\varepsilon_{0}$ is the vacuum permittivity $\left(\varepsilon_{o}=8.852 \times 10^{-14} \mathrm{~F} / \mathrm{cm}\right)$, and $\varepsilon^{\prime \prime}$ is the imaginary part of complex dielectric permittivity $\left(\varepsilon^{*}\right)$. The AC proton conductivity of the PVA:PAMPS:Triazole $(1: 1: 1)$ as a function of frequency is given in Fig. 6. As a result of typical behavior of ion conducting polymers, all curves have frequency dependent and independent regions. Frequency independent regions shift toward higher frequencies with increasing temperatures. While increases in proton conductivities are attributed to electrode polarization of the blocking electrode at low frequencies $\left(1-10^{3} \mathrm{~Hz}\right)$, they are ascribed to dispersion formation in polymers at high frequencies $\left(10^{5}-10^{6}\right) .[2,11,14,15,17,19-21,27]$ By the extrapolation of frequency independent plateau regions to zero frequency, the direct current (DC) conductivities $\left(\sigma_{\mathrm{dc}}\right)$ (i.e. Arrhenius plots) of the membranes were derived. 


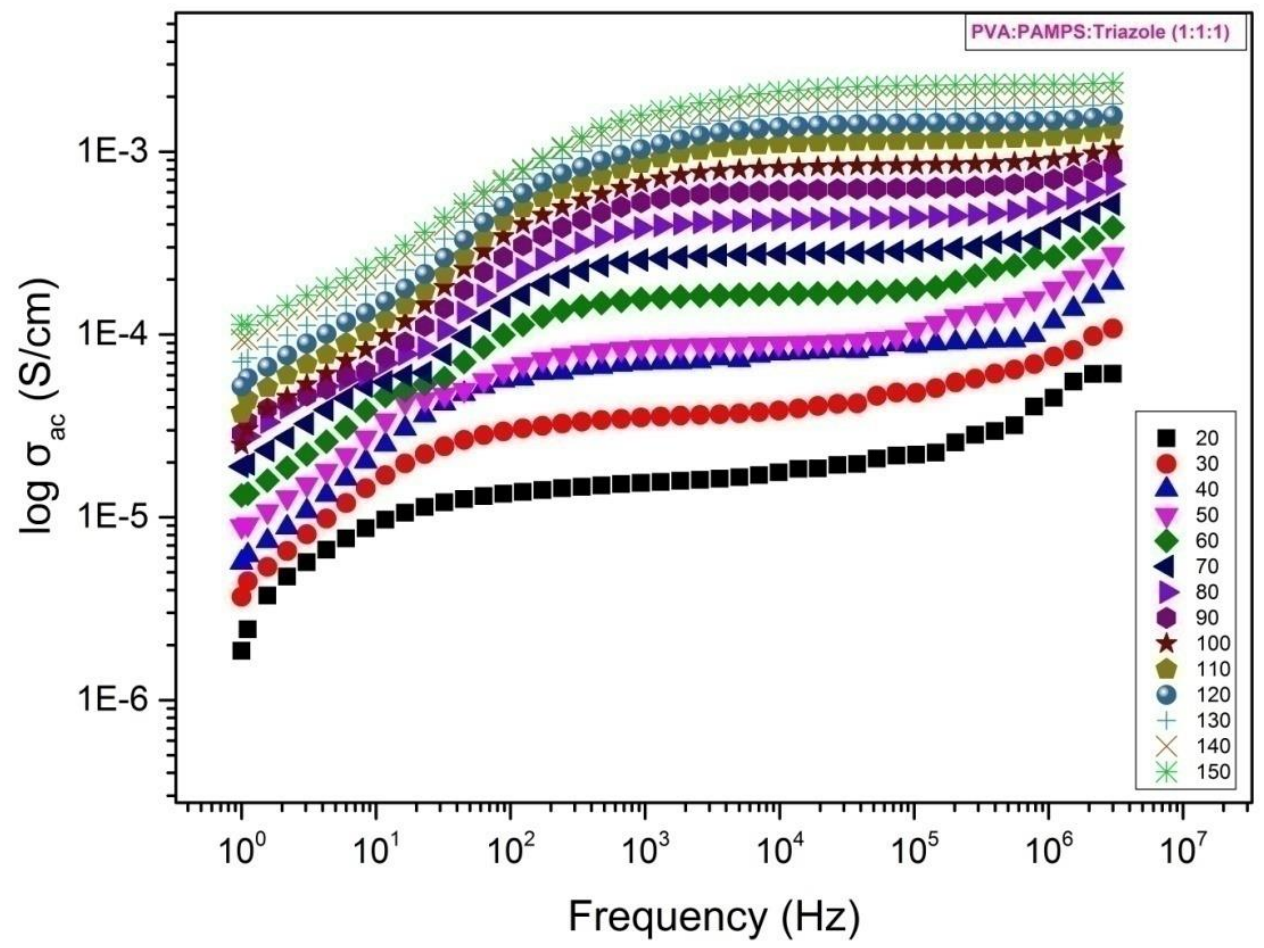

Fig. 6.AC conductivity versus frequency of anhydrous composite PVA:PAMPS:1,2,4-Triazole (1:1:1) membrane at several temperatures $\left(20-150{ }^{\circ} \mathrm{C}\right)$.

Fig. 7 presents the Arhhenius plots of the composite membranes. The results show that the the proton conductivity of the membrane with PVA:PAMPS:Triazole $(1: 1: 1)$ composition has a linear tempereature dependence between $20^{\circ} \mathrm{C}$ and $150{ }^{\circ} \mathrm{C}$. Moreover, although there are some fluctuations on proton conductivities of other membranes with temperature, all of them reach the highest conductivity at $150{ }^{\circ} \mathrm{C}$. The conductivity of PVA:PAMPS:Triazole $(1: 1: 1)$ reaches $0.002 \mathrm{~S} \mathrm{~cm}^{-1}$ at $150{ }^{\circ} \mathrm{C}$. The proton conductivity results obtained for our membranes are comparable to phosphoric acid doped PBI membranes in the literature. [1, 28, 29] 


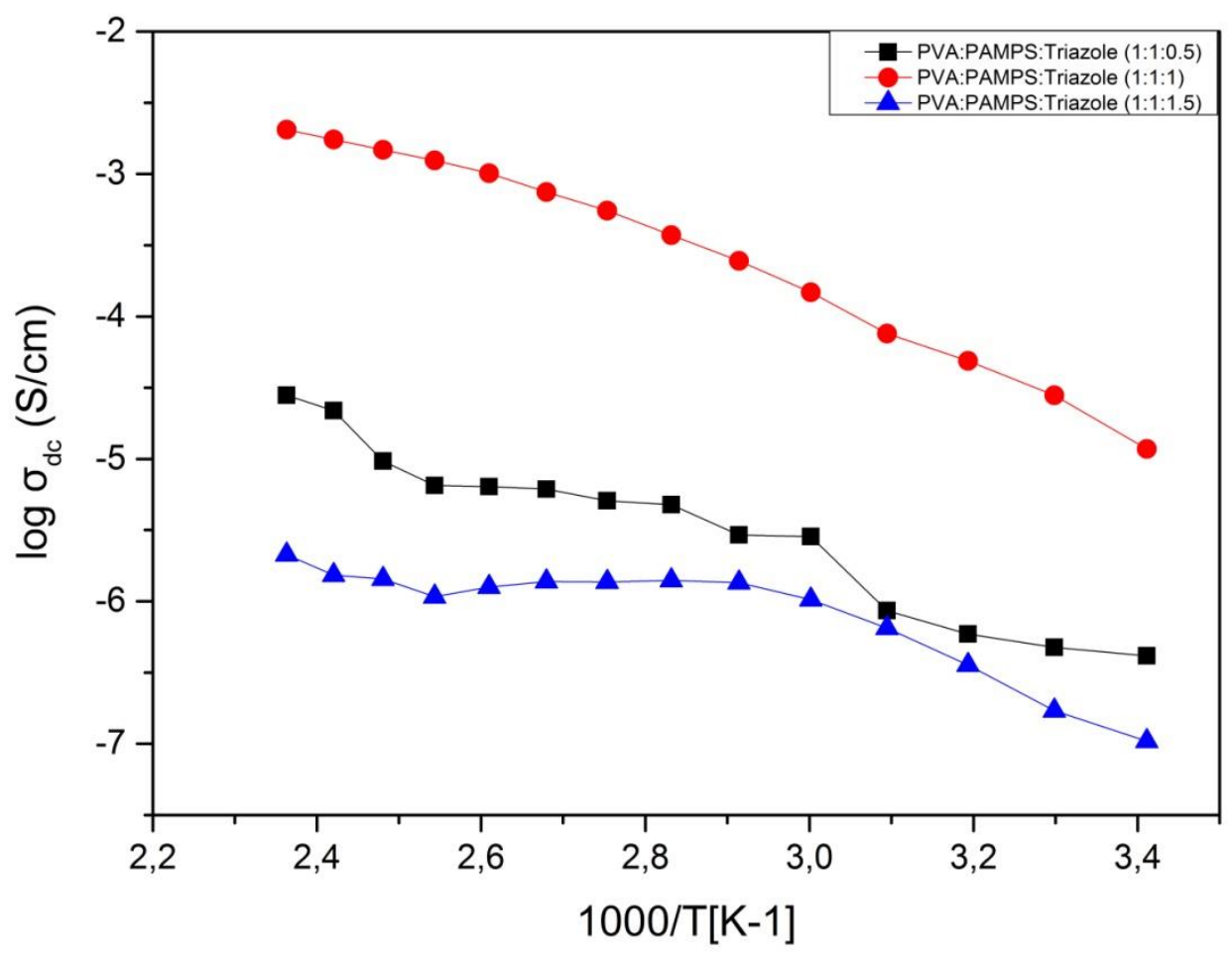

Fig. 7.DC conductivity versus reciprocal temperature of anhydrous composite PVA:PAMPS:1,2,4membranes with different compositions.

Temperature dependence of proton conductivity is given by the Arrhenius equation (Eq. 4):

$\sigma=\sigma_{0} \exp \left(-\frac{E_{a}}{k T}\right)(4)$

Where $\mathrm{E}_{\mathrm{a}}$ is the activation energy of proton conduction, $\mathrm{k}$ is the Boltzmann constant, and $\mathrm{T}$ is temperature in terms of Kelvin. The slope of the plot - i.e. $\log \sigma$ vs $1000 /$ T- gives the activation energy for proton conduction. The calculated activation energies of proton conduction for composite membranes are between 8.40 and $17.75 \mathrm{~kJ} \mathrm{~mol}^{-1}$. These results are similar to the activation energies of 1,2,4-Triazole containing membranes in the literature. In anhydrous state, in the lack of water molecules, composite membranes allow the formation of protonic defects sites and enable easily altered proton donor and acceptor functional sites. A 
heterocycle, such as imidazole and triazole, assists the proton migration since the nitrogen sites in its structure act as proton acceptor with regard to the acid group in the polymer. Based on the obtained results, the proton transfer phenomena can be described throughout the membrane as follows: During a typical proton migration, the sulfonic acid groups of PAMPS and 1,2,4-Triazole molecules serve as donor and acceptor proton carrier sites and they undergo continuous protonation/deprotonation processes by forming and breaking hydrogen bonding through their nitrogen and oxygen atoms.[13, 14, 17, 24, 29-31] (Fig. 2c.) An important implication of these findings with the data obtained from FTIR and conductivity measurement is that proton transfer occurs throughout the composite membranes by Grotthuss-type mechanism. However, the results were quite surprising and indicated that the proton conductivity of the composite membranes is not increasing with increasing acid content (namely PAMPS) in the membranes. There is an optimum mixing value for PAMPS and 1,2,4-Triazole, and the highest conductivity was collected at PAMPS:1,2,4-Triazole (1:3) molar ratio. Based on the results, we can speculate that while a well-developed proton transfer pathway can be built at this molar ratio (1:3), a suitable hydrogen bonding path cannot be established below or above of this ratio because of the pinning of molecules in themselves throughout the membranes.

\section{Conclusion}

In the present work, anhydrous proton conducting composite membranes consisting of PVA, PAMPS, and 1,2,4-Triazole were designed and fabricated. The prepared membranes are flexible, transparent and free-standing. The 1,2,4-Triazole to PAMPS ratio varied from 0.5 to 1.5 in weight. (This corresponds to 1.5 to 4.5 in terms of molar ratio.) SEM images of surfaces and cross-sections showed that all constituents are uniformly distributed through the 
membrane. TG analyses demonstrated the thermal stability of all membranes up to approximately $220{ }^{0} \mathrm{C}$. The chemical cross-linking of PVA by GA and intermolecular interaction between the constituent was verified with FT-IR. The detailed water uptake (WU) tests showed that the dimensions of the membranes are highly stable. Ion exchange capacity (IEC) studies demonstrated that the IEC values are directly related to the PAMPS content. The proton conductivities of composite membranes increase with the temperature and the temperature dependencies obey an Arrhenius behavior. Among the membranes, the membrane with PVA:PAMPS:1,2,4-Triazole (1:1:1) composition exhibits the highest proton conductivity, i.e. $0.002 \mathrm{~S} / \mathrm{cm}$ at $150{ }^{\circ} \mathrm{C}$, under anhydrous state. According to our results, it can be concluded that the proton transport in the composite membranes occurs via Grotthuss mechanism. Overall, this study clearly shows that incorporating 1,2,4-triazole agents into a suitable polymer matrix can be a very promising approach to realize membrane for HTPEMFCs. Our findings will open up new perspectives for research on novel HTPEMFC membranes based on heterocyles.

\section{Acknowledgements}

This work was supported by Abdullah Gül University Scientific Research Projects AGU-BAP under the contract No. FOA-2015-6 and partially granted by AGU-BAP under the contract No. FYL-2014-7. 


\section{References}

1. Chandan, A., et al., High temperature (HT) polymer electrolyte membrane fuel cells (PEMFC) - A review. Journal of Power Sources, 2013. 231: p. 264-278.

2. $\quad$ Erkartal, M., et al., Proton conducting poly(vinyl alcohol) (PVA)/poly (2-acrylamido2-methylpropane sulfonic acid) (PAMPS)/zeolitic imidazolate framework (ZIF) ternary composite membrane. Journal of Membrane Science, 2016. 499: p. 156-163.

3. Li, Q.F., et al., High temperature proton exchange membranes based on polybenzimidazoles for fuel cells. Progress in Polymer Science, 2009. 34(5): p. 449477.

4. Wang, Y., et al., A review of polymer electrolyte membrane fuel cells: Technology, applications, and needs on fundamental research. Applied Energy, 2011. 88(4): p. 981-1007.

5. Bozkurt, A. and W.H. Meyer, Proton-conducting poly(vinylpyrrolidon)polyphosphoric acid blends. Journal of Polymer Science Part B-Polymer Physics, 2001. 39(17): p. 1987-1994.

6. Guo, Z.B., et al., New anhydrous proton exchange membranes for high-temperature fuel cells based on PVDF-PVP blended polymers. Journal of Materials Chemistry A, 2015. 3(1): p. 148-155.

7. Padmavathi, R. and D. Sangeetha, Design of novel SPEEK-based proton exchange membranes by self-assembly method for fuel cells. Ionics, 2013. 19(10): p. 1423-1436.

8. De Almeida, N.E. and G.R. Goward, Imidazolium Trifluoromethanesulfonate sPEEK Composites for Anhydrous High Temperature Proton Exchange Membrane Fuel Cells. Polymer Electrolyte Fuel Cells 14, 2014. 64(3): p. 425-432.

9. Molla, S. and V. Compan, Nanocomposite SPEEK-based membranes for Direct Methanol Fuel Cells at intermediate temperatures. Journal of Membrane Science, 2015. 492: p. 123-136.

10. Zhao, X., H.M. Xiong, and J.S. Chen, Proton-conducting and ionic-conducting polymer electrolytes based on polyethylene Oxide(PEO). Chinese Journal of Inorganic Chemistry, 2002. 18(1): p. 63-66.

11. Sen, U., et al., Enhancement of Anhydrous Proton Conductivity of Poly(vinylphosphonic acid)-Poly(2,5-benzimidazole) Membranes via In Situ Polymerization. Macromolecular Chemistry and Physics, 2015. 216(1): p. 106-112.

12. Steininger, H., et al., Intermediate temperature proton conductors for PEM fuel cells based on phosphonic acid as protogenic group: A progress report. Physical Chemistry Chemical Physics, 2007. 9(15): p. 1764-1773.

13. Li, S.W., et al., 1H-1,2,4-triazole: An effective solvent for proton-conducting electrolytes. Chemistry of Materials, 2005. 17(24): p. 5884-5886.

14. Kim, J.D., et al., Anhydrous proton-conducting properties of Nafion-1,2,4-triazole and Nafion-benzimidazole membranes for polymer electrolyte fuel cells. Journal of the Electrochemical Society, 2007. 154(4): p. A290-A294.

15. Sen, U., et al., Anhydrous proton conducting membranes for PEM fuel cells based on Nafion/Azole composites. International Journal of Hydrogen Energy, 2008. 33(11): p. 2808-2815.

16. Zhou, Z., et al., Promotion of proton conduction in polymer electrolyte membranes by 1H-1,2,3-triazole. Journal of the American Chemical Society, 2005. 127(31): p. 10824-10825.

17. Aslan, A., et al., Intrinsically proton-conducting poly(1-vinyl-1,2,4-triazole)/triflic acid blends. Electrochimica Acta, 2009. 54(11): p. 2957-2961. 
18. Sen, U., A. Bozkurt, and A. Ata, Nafion/poly(1-vinyl-1,2,4-triazole) blends as proton conducting membranes for polymer electrolyte membrane fuel cells. Journal of Power Sources, 2010. 195(23): p. 7720-7726.

19. Qiao, J.L., T. Hamaya, and T. Okada, New highly proton-conducting membrane poly(vinylpyrrolidone)(PVP) modified poly(vinyl alcohol)/2-acrylamido-2-methyl-1propanesulfonic acid (PVA-PAMPS) for low temperature direct methanol fuel cells (DMFCs). Polymer, 2005. 46(24): p. 10809-10816.

20. Qiao, J.L., T. Hamaya, and T. Okada, Chemically modified poly(vinyl alcohol)-poly(2acrylamido-2-methyl-1-propanesulfonic acid) as a novel proton-conducting fuel cell membrane. Chemistry of Materials, 2005. 17(9): p. 2413-2421.

21. Qiao, J.L., T. Hamaya, and T. Okada, New highly proton conductive polymer membranes poly( vinyl alcohol)-2-acrylamido-2-methyl-1-propanesulfonic acid (PVAPAMPS). Journal of Materials Chemistry, 2005. 15(41): p. 4414-4423.

22. Tsai, C.E., C.W. Lin, and B.J. Hwang, A novel crosslinking strategy for preparing poly(vinyl alcohol)-based proton-conducting membranes with high sulfonation. Journal of Power Sources, 2010. 195(8): p. 2166-2173.

23. Hamaya, T., et al., Novel proton-conducting polymer electrolyte membranes based on PVA/PAMPS/PEG400 blend. Journal of Power Sources, 2006. 156(2): p. 311-314.

24. Kim, J.D., et al., Physico-Chemical Properties of Highly Flexible Temperature Tolerant Anhydrous Nafion-1,2,3-Triazole Blend Membranes. Journal of the Electrochemical Society, 2010. 157(12): p. B1872-B1877.

25. Dai, C.A., et al., Polymer actuator based on PVA/PAMPS ionic membrane: Optimization of ionic transport properties. Sensors and Actuators a-Physical, 2009. 155(1): p. 152-162.

26. Amirilargani, M. and B. Sadatnia, Poly(vinyl alcohol)/zeolitic imidazolate frameworks (ZIF-8) mixed matrix membranes for pervaporation dehydration of isopropanol. Journal of Membrane Science, 2014. 469: p. 1-10.

27. Sen, U., et al., Proton Conducting Polymer Blends from Poly(2,5-Benzimidazole) and Poly(2-Acrylamido-2-methyl-1-propanesulfonic acid). Journal of Applied Polymer Science, 2011. 120(2): p. 1193-1198.

28. Asensio, J.A., E.M. Sanchez, and P. Gomez-Romero, Proton-conducting membranes based on benzimidazole polymers for high-temperature PEM fuel cells. A chemical quest. Chemical Society Reviews, 2010. 39(8): p. 3210-3239.

29. Ossiander, T., et al., Influence of the size and shape of silica nanoparticles on the properties and degradation of a PBI-based high temperature polymer electrolyte membrane. Journal of Membrane Science, 2014. 454: p. 12-19.

30. Lei, M., et al., Anhydrous proton conducting composite membranes containing Nafion and triazole modified POSS. Electrochimica Acta, 2014. 149: p. 206-211.

31. Li, W., et al., Decorating titanate nanotubes with protonated 1,2,4-triazole moieties for anhydrous proton conduction. Journal of Colloid and Interface Science, 2014. 432: p. 26-30. 